\title{
Maximum Power Extraction of Solar PV system using DC-DC Buck converter and backstepping control based on P\&O MPPT algorithm
}

\author{
Manal KOUIHI, Mohamed MOUTCHOU, Abdelhafid AIT ELMAHJOUB \\ Research Group of Smart Control, Diagnostic and Renewable Energy "SCDRE”, Laboratory of Complex Physical \\ Systems (LCCPS), ENSAM, Hassan II University in Casablanca, Morocco
}

\begin{abstract}
This paper presents the system allowing the extraction of maximum power from a sun based on solar photovoltaic module and backstepping control based on a P\&O MPPT algorithm for a DC-DC buck converter. The aim of this research work is to determinate quickly the optimal PV Module working point which allowed to extract the maximum power. This work, based on a usage of a DC-DC buck converter to control the working point by adjusting PV voltage trough a duty cycle. In order to achieve our goal, we used the combination of perturb and observe $(\mathrm{P} \& \mathrm{O})$ algorithm and DC-DC buck converter with backstepping control. This model was implemented in Matlab/Simulink software, the results of simulation prove its effectiveness in term of maximum power tracking dynamics for different irradiance and temperature profiles.
\end{abstract}

\section{Introduction}

Since the industrial revolution, the energy mix of most countries across the world has become dominated by fossil fuels [2]. This has major implications for the global climate, as well as for human health. This is why the whole world is moving towards low-carbon sources and renewable energy.

At our national level, Morocco also has adopted this strategy of ecological modernization with an ambitious program aimed at increasing the share of renewable energies (for electricity needs) in the national energy network to $42 \%$ by $2021,52 \%$ by 2030 and $100 \%$ by 2050 (Fig1) [4], by launching megaprojects in areas related to solar and wind energy [5-6-7].

These energies: photovoltaic energy and wind energy present several challenges because of its intermittent and variable nature during the day and from one season to another, this why scientific researchers try through their researchers to make the use and conversion of these energies more efficient, profitable, competitive and therefore more interesting. The primary concern of the researchers is to increase the efficiency of the PV energy conversion operation by implementing high performance MPPT algorithms and the design of efficient energy converter structures. There are about twenty methods for tracking the Maximum Power Point (MPPT), whose efficiency and speed vary [8]. The most commonly encountered methods are:

- $\quad$ Perturb and Observe (P\&O) [9-15]

- $\quad$ The IncCond (Incremental conductance) [15]

- The Fractional Open-circuit Voltage method (FOC)

- The Fractional Short-circuit Current method (FSC)

In this research, we choose to use the P\&O MPPT algorithm for designing our MPPT control based on
Buck structure for DC-DC CONVERSION. In order to achieve a good control performance in term of dynamics and precision, we used the backstepping technique for the control design of the DC-DC buck converter. In the first, we present the PV Module model and its behaviour for variation of radiation and temperature, in the third section we present the DC-DC Buck converter model, then in the fourth section, we present the DC-DC Buck converter control design using backstepping technique, after that in the fifth section, we present our MPPT algorithm based on the principal of Perturb and Observe (P\&O), finally sixth section we give the simulation results of the PV conversion control, followed by conclusion [1].

\section{$100 \%$ MOROCCO}

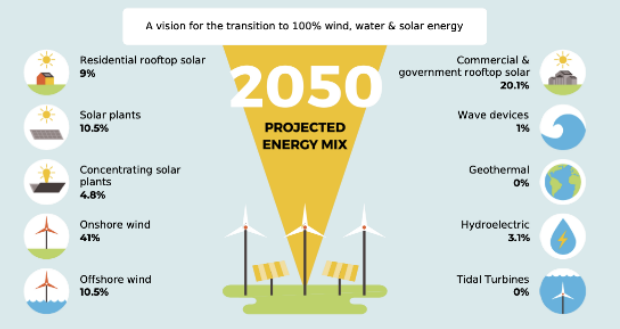

Fig.1. The vision of renewable energy with $100 \%$ by 2050 [5]

\section{Model of photovoltaic module}

A photovoltaic PV generator is the whole assembly of solar cells, connections, protective parts, supports, etc. In the present modeling, the focus is only on cell/module/array. Solar cells consist of a PN junction fabricated in a thin wafer or layer of semiconductor (usually silicon) [16]. In the dark, the I-V output characteristic of a solar cell has an exponential 
characteristic similar to that of a diode. When solar energy (photons) hits the solar cell, with energy greater than the band gap energy of the semiconductor, electrons are knocked loose from the atoms in the material, creating electron-hole pairs. These carriers are swept apart under the influence of the internal electric fields of the PN junction and create a current proportional to the incident radiation [16]. When the cell is short circuited, this current flows in the external circuit; when open circuited, this current is shunted internally by the intrinsic PN junction diode. The characteristics of this diode therefore set the open circuit voltage characteristics of the cell [16].

\subsection{Modelling the solar cell}

The In this research, we use the single diode equivalent circuit model as showing in Fig.2, to simulate PV Module voltage-current (V-I) behavior [1]. The main model parameters comprise the photogenerated current (Iph), saturation current (Iss), diode ideality factor $(\eta)$. Series resistance $(R s)$ and shunt resistance $(R \mathrm{p})$. These parameter values are given in Table 1 .

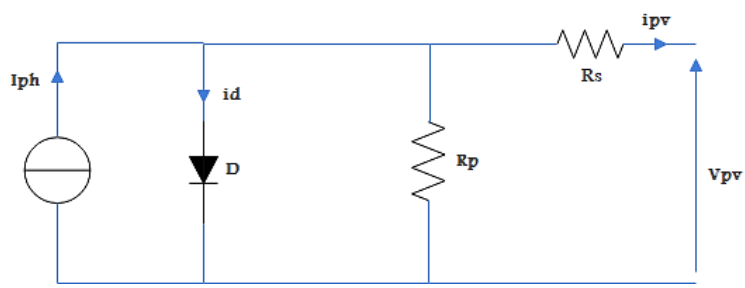

Fig. 2. The equivalent circuit of a PV cell

The photovoltaic module can be modeled mathematically as given in equations:

- Saturation current:

$$
I S S=I r S \cdot\left(\frac{T}{T n}\right)^{3} \cdot \exp \left[\frac{q \cdot E g \cdot\left(\frac{1}{T n}-\frac{1}{T}\right)}{\eta \cdot K}\right]
$$

- Photo-current:

$$
I p h=[I s c+k i \cdot(T-298)] \cdot \frac{G}{1000}
$$

- Reverse saturation current:

- Shunt current:

$$
I r s=\frac{I s c}{\exp \left[\frac{q . V o c}{\eta \cdot N S . K . T}\right]-1}
$$

$$
I s h=\left(\frac{V p v+R s . i p v}{R p}\right)
$$

In this model the output current can be expressed as follows:

$$
I p v=I p h-I s s *\left(\exp \left(\frac{q \cdot(V p v+R s * i p v)}{\eta \cdot K \cdot T \cdot N s}\right)-1\right)-I s h
$$

Where:

$\mathbf{q}:$ is the elementary charge $\left(\mathrm{q}=1,602 \cdot 10^{-19} \mathrm{c}\right)$

$\mathbf{K}$ : is the Boltzmann constant $\left(\mathrm{K}=1,38 \cdot 10^{-23} \mathrm{~J} \cdot \mathrm{K}^{-1}\right)$

G: is the irradiance $\left(\mathrm{W} / \mathrm{m}^{2}\right)$

$\mathbf{T}$ : is the temperature $(\mathrm{K})$

Tn: is the temperature for standard test conditions

Isc: is the short circuit current (A)

Voc: is the open circuit voltage (V)

Ns: number of cells connected in series

Np: number of PV modules connected in parallel

Eg: Band gap energy of the semiconductor $(1,1 \mathrm{eV})$

The photogenerated current iph and open circuit voltage Voc can be calculated from rated parameter's value of the PV module, as follows:

Table 1. The PV module parameters

\begin{tabular}{|c|l|c|c|}
\hline \multicolumn{2}{|c|}{ Parameters } & Values & Units \\
\hline $\mathrm{P}$ & Nominal power & 60 & $\mathrm{~W}$ \\
\hline Voc & Open circuit voltage & 21,1 & $\mathrm{~V}$ \\
\hline $\mathrm{Isc}$ & Short circuit current & 3,8 & $\mathrm{~A}$ \\
\hline $\mathrm{ki}$ & $\begin{array}{l}\text { Current temperature } \\
\text { coefficients }\end{array}$ & 0,0025 & $\mathrm{~mA} / \mathrm{K}$ \\
\hline $\mathrm{kv}$ & $\begin{array}{l}\text { Voltage temperature } \\
\text { coefficients }\end{array}$ & $-0,08$ & $\mathrm{~V} / \mathrm{K}$ \\
\hline $\mathrm{Rs}$ & Serie resistance & 0,18 & $\Omega$ \\
\hline $\mathrm{Rp}$ & Parallel resistance & 360 & $\Omega$ \\
\hline$\eta$ & Ideality factor of the diode & 1,36 & - \\
\hline
\end{tabular}

\subsection{Influence of temperature and irradiance}

In order to illustrate the PV model behavior, we present below in Figure 3 to Figure 6, the current-voltage and power-voltage curves of the model in case of various temperature value with constant irradiation as shown in Figure 3 and Figure 4, and in case of various value of irradiation with constant temperature value as shown in Figure 5 and Figure 6.

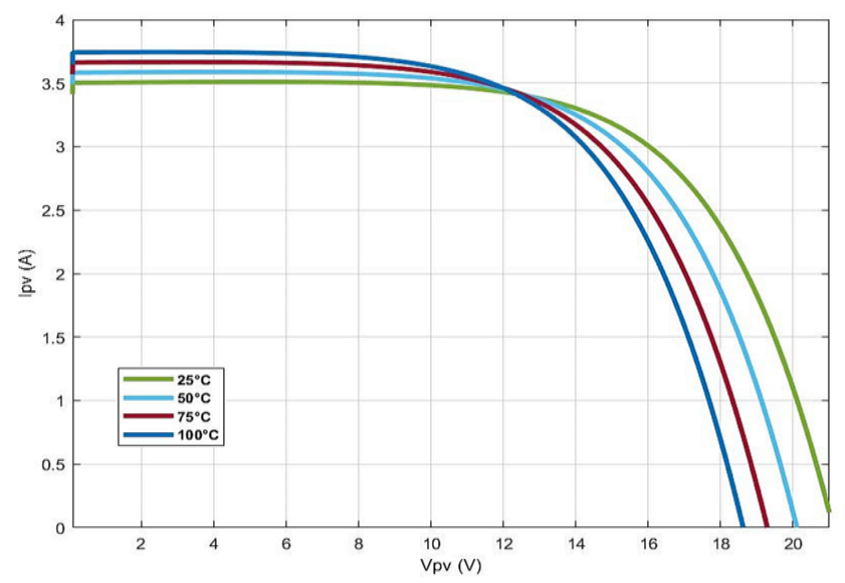

Fig.3. Ipv-Vpv PV Module curves for irradiance $E=1000$ $\mathrm{W} / \mathrm{m} 2$, and for different temperature values 


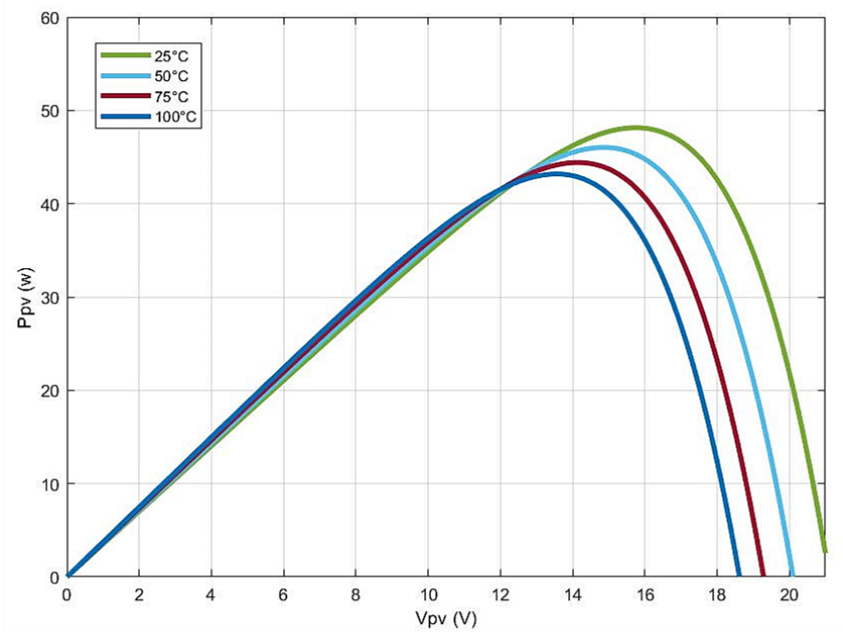

Fig.4. Ppv-Vpv PV Module curves for irradiance $E=1000$ $\mathrm{W} / \mathrm{m} 2$, and for different temperature values

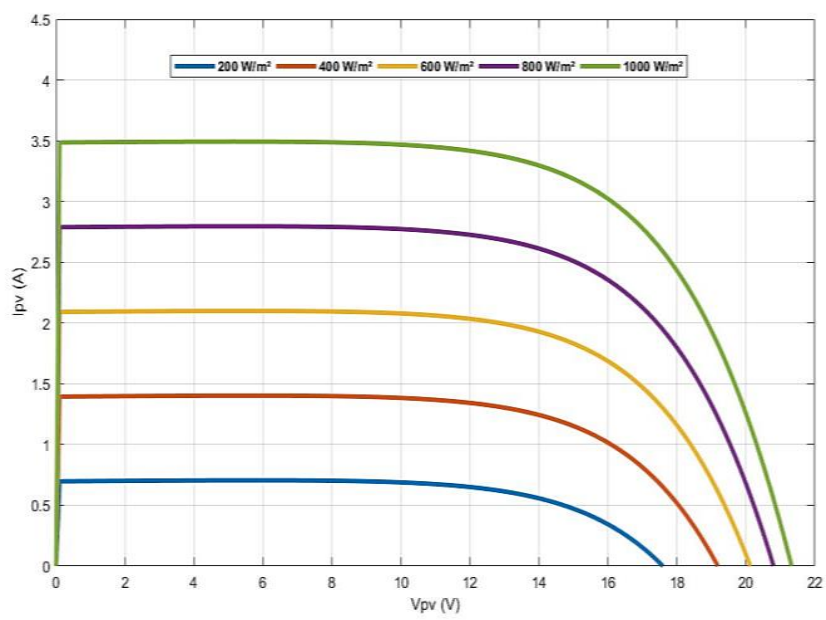

Fig.5. Ipv-Vpv PV Module curves for temperature $\mathrm{T}=25^{\circ} \mathrm{C}$, and for different irradiance values

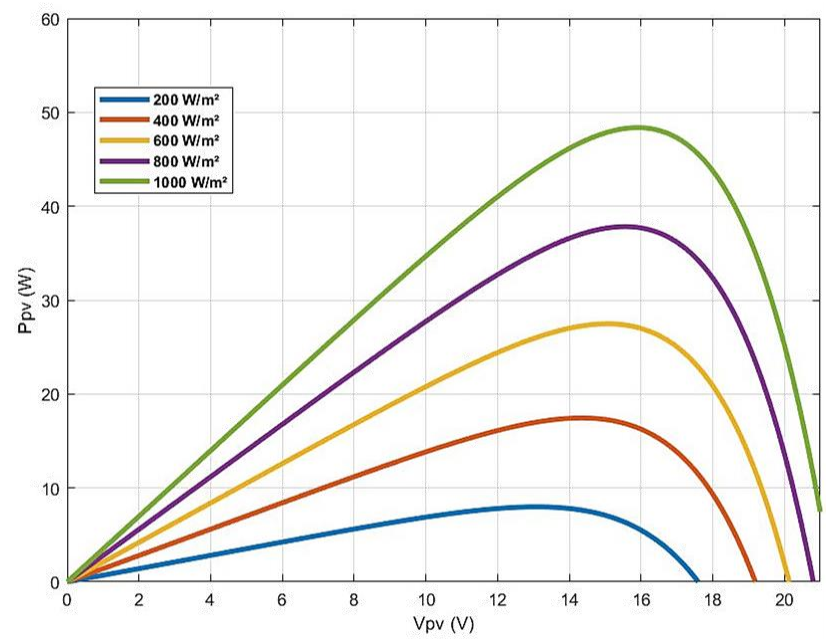

Fig.6. Ipv-Vpv PV Module curves for temperature $\mathrm{T}=25^{\circ} \mathrm{C}$, and for different irradiance values

\section{Buck converter design}

A buck converter (step-down converter) is a DC-DC power converter which steps down voltage (while stepping up current) from its input (supply) to its output (load). It is class of switched-mode power supply, typically containing at least two semiconductors (a diode and a transistor) and at least one energy storage voltage ripple, filters made of capacitors are normally added to the converter output (load-side filer) and input (supply-side filter) [12].

In this work, we choose to use a DC-DC buck converter as showing in Fig.7 to achieve load adaptation in order to make PC Module work at its maximum power point. We consider this converter is more adequate for PV-MPPT control, because it allows us to control the input voltage $\mathrm{Ve}$, which is equal to the PC Module voltage Vpv.

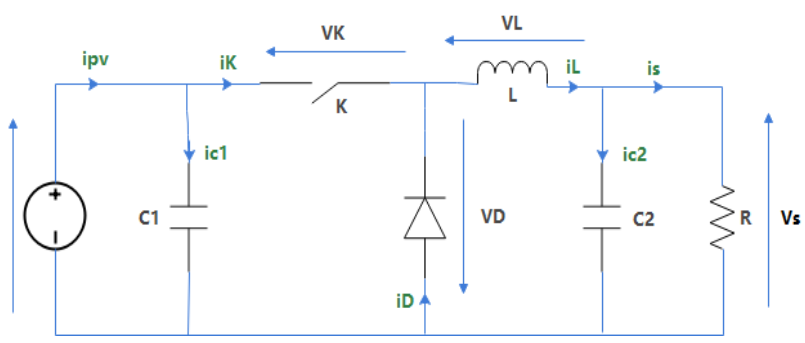

Fig.7. Buck converter circuit

The parameters values used are given in this table below:

Table 2. The Buck converter parameters

\begin{tabular}{|c|c|c|c|}
\hline \multicolumn{2}{|c|}{ Parameters } & Values & Units \\
\hline $\mathrm{C} 1$ & Input capacitor & 1000 & $\mu \mathrm{F}$ \\
\hline $\mathrm{C} 2$ & Output capacitor & 1000 & $\mu \mathrm{F}$ \\
\hline $\mathrm{L}$ & Input inductance & 100 & $\mathrm{mH}$ \\
\hline
\end{tabular}

The switch component $\mathrm{K}$ is commuted periodically as described below:

- $\quad$ K On and D Off, for $(0 \leq t \leq d T)$ :

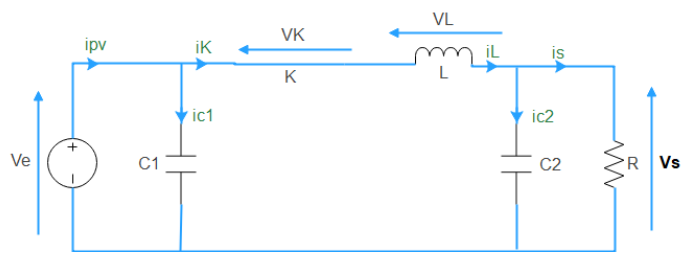

Fig.8. Buck converter for $(0 \leq \mathrm{t} \leq \mathrm{dT})$

In this phase the current in the inductance is given by the following equation:

$$
\frac{d i L}{d t}=\frac{\mathrm{ve}-\mathrm{vs}}{L}
$$

The Ipv current is given by the following equation:

$$
\frac{d V e}{d t}=\frac{\mathrm{iL}-\mathrm{ipv}}{\mathrm{C} 1}
$$

The output voltage Vs is given by the following equation:

$$
\frac{d V s}{d t}=\frac{\mathrm{iL}-\mathrm{is}}{\mathrm{C} 2}
$$


- $\quad$ K Off and D On, for $(\mathrm{dT} \leq \mathrm{t} \leq \mathrm{T})$ :

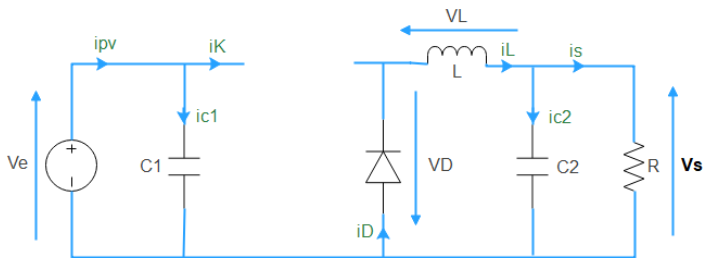

Fig.9. Buck converter for $(\mathrm{dT} \leq \mathrm{t} \leq \mathrm{T})$

In this phase we present the equation of the input voltage:

$$
\frac{d V e}{d t}=-\frac{\mathrm{ipv}}{\mathrm{C} 1}
$$

The current variation in the inductance is given by following equation:

$$
\frac{d i L}{d t}=\frac{-\mathrm{vs}}{L}
$$

The output voltage Vs is given by the following equation:

$$
\frac{d V s}{d t}=\frac{\mathrm{iL}-\mathrm{is}}{\mathrm{C} 2}
$$

Based on these aquations the Buck converter averaging model is as below:

$$
\left\{\begin{array}{l}
\frac{d i L}{d t}=\frac{\mathrm{ve}}{L} \mathrm{~d}-\frac{\mathrm{vs}}{L} \\
\frac{d V e}{d t}=\frac{\mathrm{iL}}{\mathrm{C} 1} d-\frac{\mathrm{ipv}}{\mathrm{C} 1} \\
\frac{d V s}{d t}=\frac{\mathrm{iL}-\mathrm{is}}{\mathrm{C} 2}
\end{array}\right.
$$

\section{Buck converter backstepping control}

In this section we will give the study that allows determining the control law of the Buck converter offering desired performances. This control will help us to achieve the main goal, which is the extraction of maximum photovoltaic power, this control will be designed in two successive steps, and through a virtual variable command [1]. This control will be used to adjust output PV voltage in order to perform maximum power tracking.

\subsection{First step: input variable control}

In this step we design the control that ensures the good output voltage. So, we define below the first tracking error:

$$
e_{1}=V_{s}-V_{\text {sref }}
$$

The error dynamic is given by:

$$
\dot{e_{1}}=\dot{V}_{s}-\dot{V}_{\text {sref }}
$$

Based on the equation (12) we can express the error dynamic as below:

$$
\dot{e_{1}}=\frac{\mathrm{iL}-\mathrm{is}}{\mathrm{C} 2}-\dot{V}_{\text {sref }}
$$

To ensure the first step control stability, we choose the Lyapunov Candidate Function (LCF) as following:

$$
V_{1}=\frac{1}{2} e_{1}^{2}
$$

The LCF dynamic is given as below:

$$
\begin{gathered}
\dot{V}_{1}=e_{1} \cdot \dot{e}_{1} \\
\dot{V}_{1}=e_{1} \cdot\left(\frac{\mathrm{iL}-\mathrm{is}}{\mathrm{C} 2}-\dot{V}_{\text {sref }}\right)
\end{gathered}
$$

In order to have $\dot{V}_{1}<0$, we supposed that:

$$
\dot{e}_{1}=-\mathrm{k}_{1} e_{1}
$$

Where $\mathrm{k} 1$ is a positive constant

Based on (17) and (19), we can conclude this:

$$
\dot{V}_{1}=-\mathrm{k}_{1} e_{1}^{2}<0
$$

From (15) and (19), we obtain the following equation:

$$
\frac{\mathrm{iL}}{\mathrm{C} 2}-\frac{\mathrm{is}}{\mathrm{C} 2}-\dot{V}_{\text {sref }}=-\mathrm{k} 1 e_{1}
$$

We consider the following virtual variable command $\alpha$, ensuring first step stability:

$$
\alpha=\frac{\mathrm{iL}}{\mathrm{C} 2}
$$

In order to have a stable tracking error dynamic, we impose the following reference control of the virtual variable:

$$
\alpha r e f=-\mathrm{k} 1 e_{1}+\frac{\text { is }}{\mathrm{c} 2}+\dot{V}_{\text {sref }}
$$

\subsection{Second step: virtual variable control}

In this step we try to stabilize the tracking error of the following virtual command:

$$
e_{2}=\alpha-\alpha_{r e f}
$$

After derivation, we have the following dynamic equations of virtual control error $e_{2}$ :

$$
\dot{e}_{2}=\dot{\alpha}-\dot{\alpha} r e f
$$

From (12) and (22), we can express the virtual control error as below: 


$$
\dot{e}_{2}=\frac{1}{\mathrm{C} 2}\left(\frac{\mathrm{ve}}{L} \mathrm{~d}-\frac{\mathrm{vs}}{L}\right)-\dot{\alpha}_{r f}
$$

The second LCF of global control is:

$$
V_{2}=\frac{1}{2} e_{1}^{2}+\frac{1}{2} e_{2}^{2}
$$

After derivation we obtain:

$$
\dot{V}_{2}=e_{1} e_{2}-\mathrm{k} 1 e_{1}{ }^{2}+e_{2} \cdot \dot{e}_{2}
$$

In order to have $\dot{V}_{2}<0$, we supposed that:

$$
-\mathrm{k}_{2} e_{2}^{2}=e_{1} e_{2}+e_{2} \cdot \dot{e}_{2}
$$

Where $\mathrm{k} 2$ is a positive constant.

So, we have to impose this following control law:

$$
\dot{e}_{2}=-\mathrm{k}_{2} e_{2}-e_{1}
$$

From (26) and (30), we determinate the expression of control that ensure the stabilization of the buck converter control.

$$
d=\frac{\mathrm{LC} 2}{\mathrm{Ve}}\left[-\mathrm{k}_{2} e_{2}-e_{1}+\frac{\mathrm{Vs}}{\mathrm{LC} 2}+\dot{\alpha}_{r e f}\right]
$$

\section{Maximum Power Point Tracking algorithm}

To improve the efficiency of the solar panel we use MPPT, in the present work we chose to use Perturb and Observe (P\&O) algorithm [6].

The perturb and observe (P\&O) algorithm is generally the most commonly applied in the control of MPPT of the PV generator. It had simple structure, low cost, easy to implement, reduced number of parameters, the possibility to introduce improvements and may result in top-level efficiency [9].

This algorithm (Fig.11) is depending on investigating the relation between PV module output pawer and its voltage. The behavior of solar panel indicating MPP and operating principle is shown in (Fig.10) which indicates that the resulting change of PV power is observed as follows:

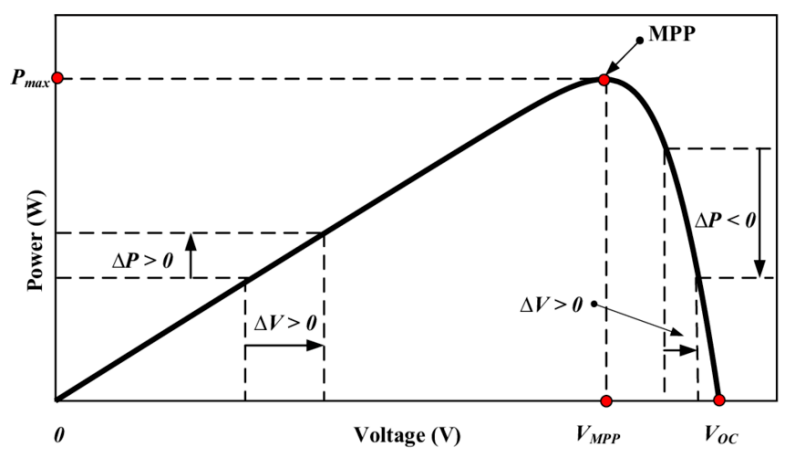

Fig.10. Characteristic curves of P\&O MPPT technique [15]
If the PV module operating point is on the left side of the curve ( $\Delta \mathrm{Pn} / \Delta \mathrm{Vn}$ is positive), which means the $\mathrm{PV}$ module output power increases, the perturbation of the PV module voltage should also be increased toward the MPP.

$\Delta \mathrm{Pn}>0$ :

- $\quad \Delta \mathrm{Vn}>0$ : Should increased

- $\quad \Delta \mathrm{Vn}<0$ : Should decreased

If the operating point of the module was on the right side of the curve $(\Delta \mathrm{Pn} / \Delta \mathrm{Vn}$ is negative), then the perturbation of the PV module voltage should be decreased toward the MPP.

$\Delta \mathrm{Pn}<0$ :

- $\quad \Delta \mathrm{Vn}<0:$ Should increased

- $\quad \Delta \mathrm{Vn}>0$ : Should decreased

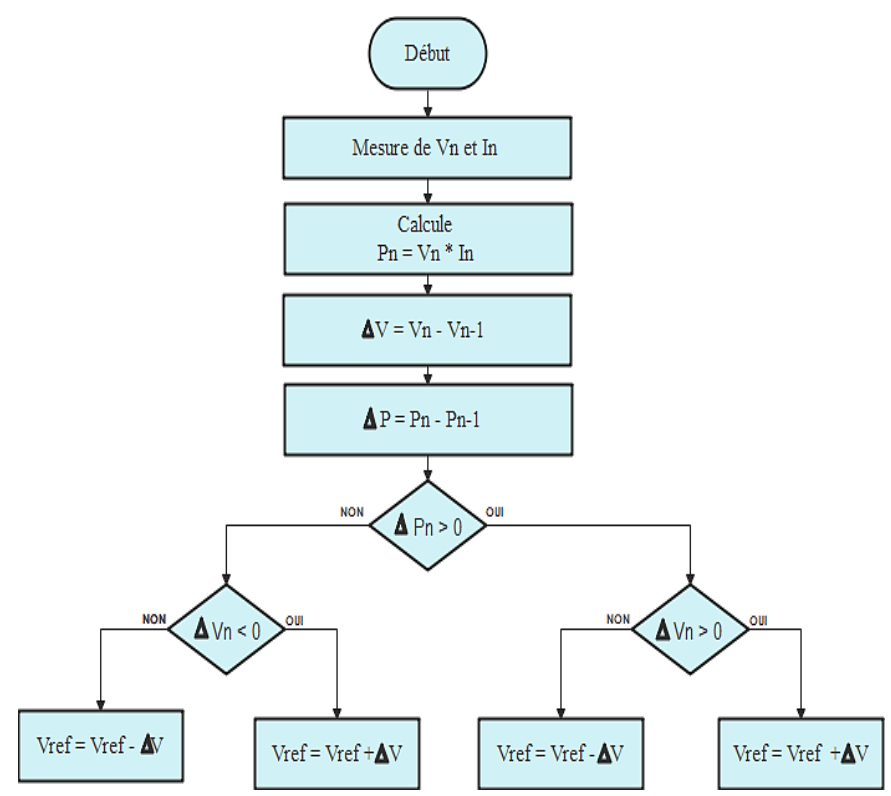

Fig.11. Flow Chart of $\mathrm{P} \& \mathrm{O}$ MPPT

For better performance and in order to have a precise and fast MPP tracking, we must correctly choose the step of Vref increasing and decreasing. In this work we take a constant step equal to 0.001 .

\section{Simulation Results: Matlab/Simulink}

In this section we present the validation of our PV conversion control, whose structure is given in

Fig.12. In order to verify the effectiveness of the adopted solution, we have performed a set of simulation tests. The control validation is made, in first with different values of irradiance which are respectively in following intervals: $\left[100,600,200,400 \mathrm{~W} / \mathrm{m}^{2}\right]$, and in the second with different temperature which are $\left[60,25,10,40^{\circ} \mathrm{C}\right]$.

The determination of DC-DC converter load $\mathrm{R}_{\text {load }}$ is made by considering the steady state of the converter. When can establish following equation that represent $\mathrm{R}_{\text {load }}$ in function of duty $(d)$ : 


$$
\mathrm{R}_{\text {load }}=\mathrm{d}^{2} \frac{\operatorname{Impp}}{V m p p} \quad \text { Where: } 0<d<1
$$

So, we have to choose the resistance load while respecting this:

$$
\mathrm{R}<\frac{I m p p}{V m p p}
$$

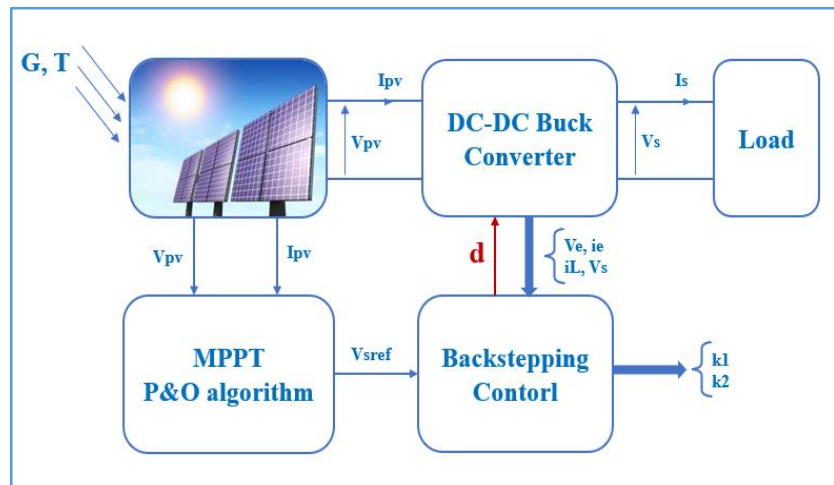

Fig.12. Structure of the MPPT- Backstepping control

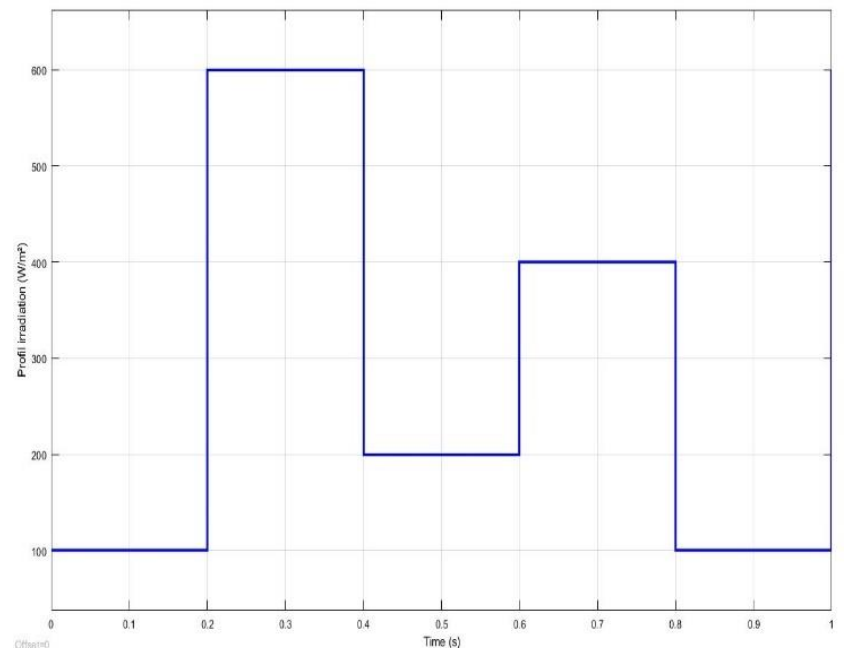

Fig.13. Profile irradiance

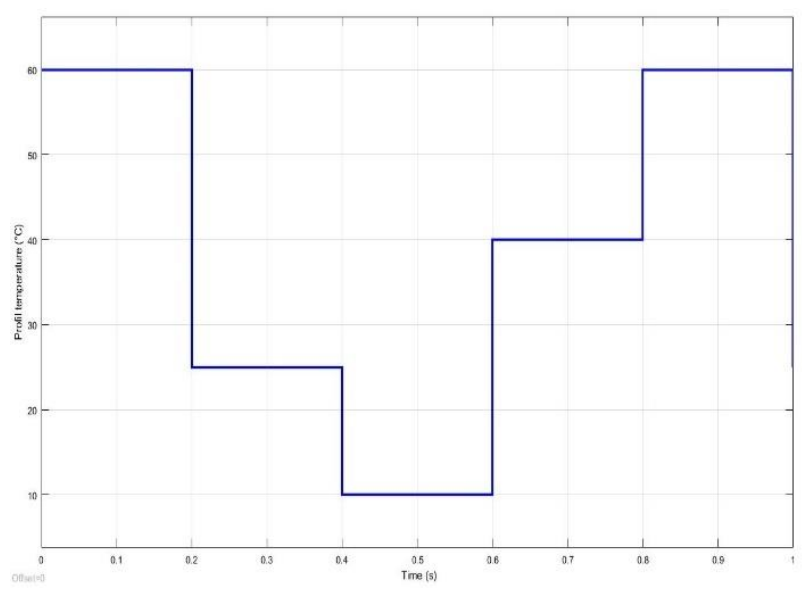

Fig.14. Profile temperature

We can see in Fig.15 that the control ensures a fast and precise tracking of the maximum power of PV Module comparison with the MPP power.

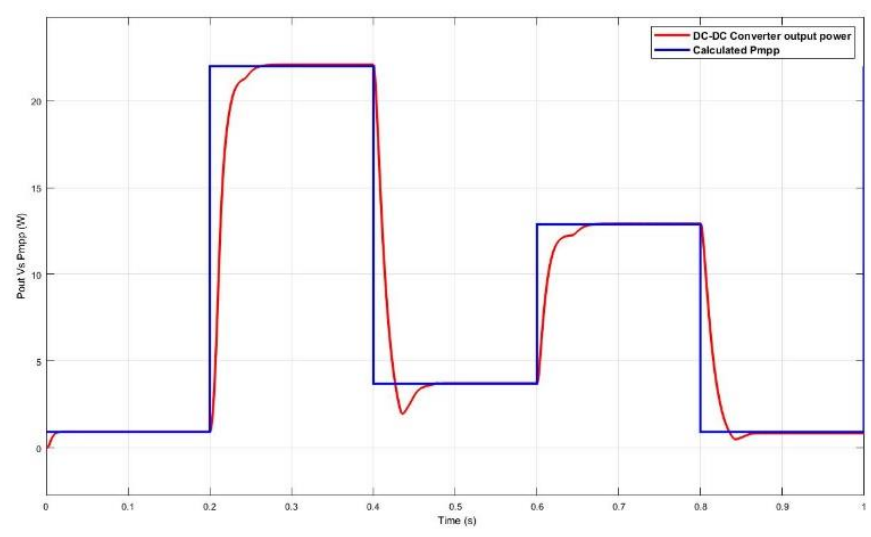

Fig.15. DC-DC Converter output power and calculated Pmpp

Fig. 16 and Fig. 17 shows that PV voltage track correctly the reference voltage.

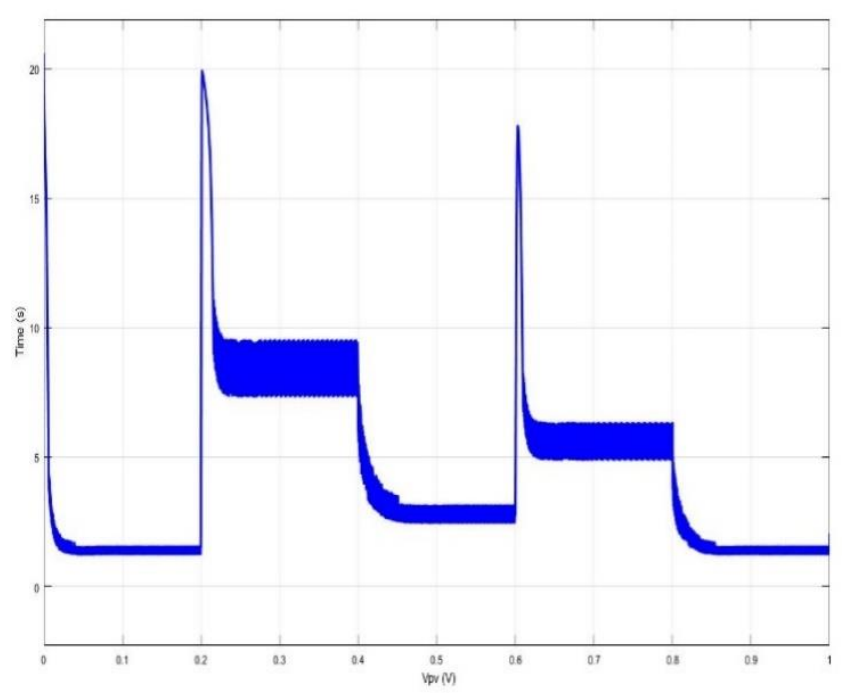

Fig.16. PV Voltage

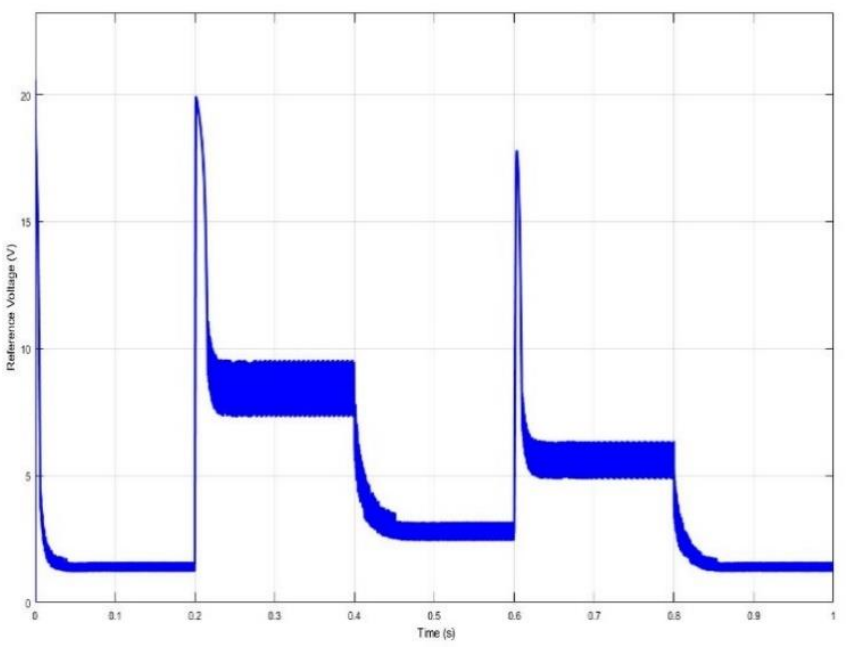

Fig. 17. Reference voltage 
Fig.18, Fig.19, and Fig.20 present respectively the inductance current, the output current and output voltage.

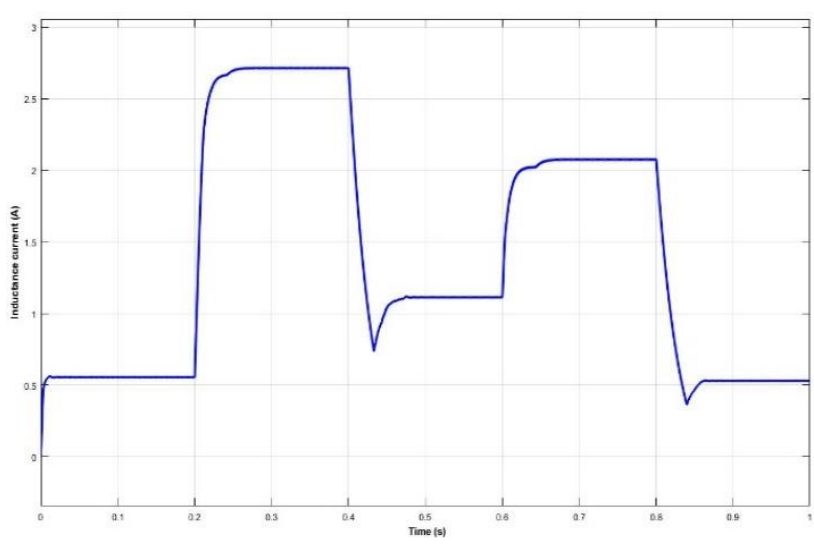

Fig.18. Inductance current

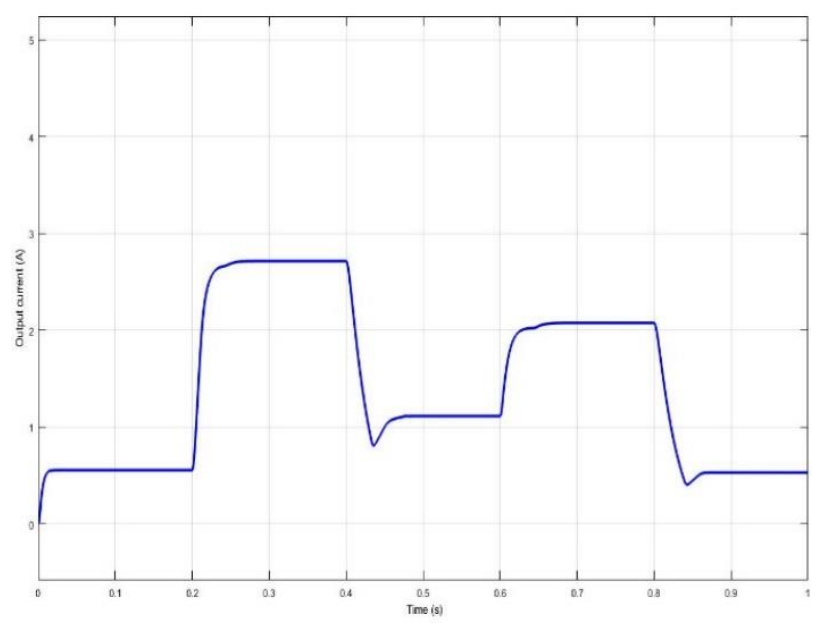

Fig.19. Output current

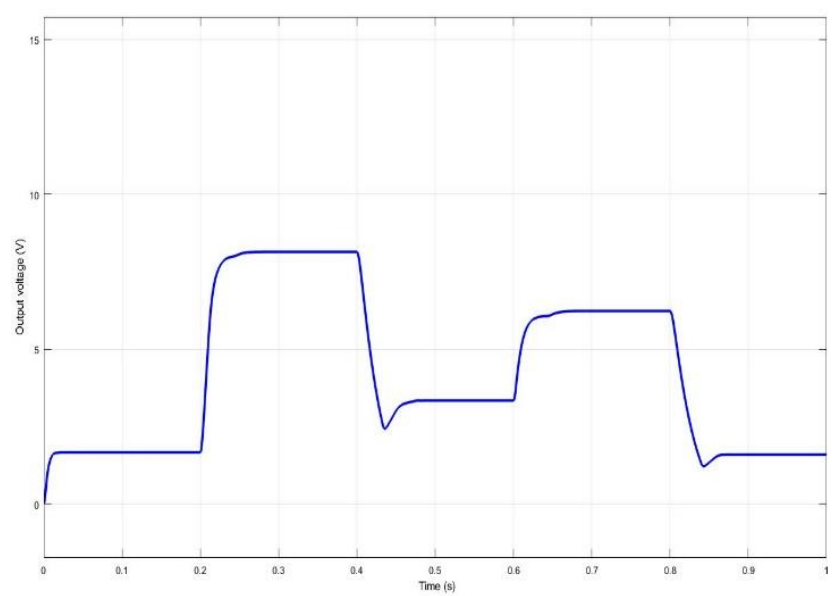

Fig.20. Output Voltage (Vs)

\section{Conclusion}

This article brings to light the steps taken to model the photovoltaic module from equivalent circuit and the equations of a solar cell. The photovoltaic module which is modeled with Simulink is then coupled the P\&O
MPPT system, Backstepping control, and the DC-DC Converter.

In this paper, we developed a control based, in first par, on MPPT Algorithm using Perturb and Observe (P\&O) technique, improved by reducing calculation time, by taking in consideration voltage and current ripples and by correctly choosing Voltage reference increasing step, and in second part, on Backstepping technique to control DC-DC Buck Converter, that provide good output voltage tracking to its voltage reference given by the MPPT Algorithm. As we have shown through simulations, this command gave good results in terms of stability, tracking quality, accuracy, and dynamic speed. The validation through simulation is done assuming hard profile of atmospheric conditions variation, more than it is in real conditions (with a large variation of temperature and irradiance, and it is made all this simulation conditions and results proof the effectiveness of our solution of conversion and MPPT control of photovoltaic energy.

\section{References}

1. M.Moutchou, A.Jbari, IJECE, Fast photovoltaic IncCond-MPPT and backstepping control, using DC-DC Boost converter, 10 (2020)

2. Renewable energy in emergent countries: lessons from energy transition in Morocco, Energy, Sustainability and Society, 2017 (https://energsustainsoc.biomedcentral.com)

3. S. Zafar, Renewable Energy in Morocco, EcoMENA, 2019.

(https://www.ecomena.org/renewable-energy-inmorocco/)

4. Energy strategies and policies in North Africa: Morocco, the Eldorado of renewable energies, BearingPoint, (https://www.bearingpoint.com/frfr/blogs/energie/morocco-the-eldorado-ofrenewable-energies/)

5. Z.Shahan, Morocco Aims For 50\% Renewable Energy By 2030, CleanTechnica, 2021. (https://cleantechnica.com/2021/01/22/moroccoaims-for-50-renewable-energy-by-2030/)

6. M.Kmaran, M.Mudassar, M.Rayyan Fazal, M.Usman, M.Bilal, R.Asghar, JKSU-ES, Implementation of improved Perturb \& Observe MPPT technique with confined search space for standlone photovoltaic system, 32 (2020)

7. T.Kouskou, A.Allouhi, B.Belattar, A.Jamil, T.El Rhafiki, Y.Zerouali, RSER, Renewable energy potential and national policy directions for sustainable development in Morocco, 47 (2015)

8. C.Chukwuka, K.A.Folly, IJRR, Technical and economic modelign of the $2.4 \mathrm{~kW}$ Grid-Tie residential Photovoltaic System, 3,2 (2013)

9. T.Parasad Sahu, T.V.Dixit, R.Kumar, AEEE, Simulation and Alalysis of Perturb and Observe MPPT Algorithm for PV array Using CUK Converter, 4, 2(2014) 
10. Infinenon Technologies North America, Buck converter design, (2013)

11. A.Belkaid, I.Colak, K.Kayisli, EE, Implementation of a modified P\&O-MPPT algorithm adapted for varying solar radiation conditions, 10 (2016)

12. S.Yang, Thesis, Modelling and control of a buck converter, (2011)

13. X.H.Nguyen, M.P.Nguyen, ESR, Mathematical Modeling of photovoltaic cell/module/arrays with tags in Matlab/Simulink, 10 (2015)

14. R.Hernanz, C.Martin, Z.Belver, L.Lesaka, Z.Guerrero, E.P.Pérez, ICREPQ, Modellinf of photovoltaic module, 10 (2010)

15. M.Shazly, A.S.Monstar, Reaserch Article, A comparative study of $\mathrm{P} \& \mathrm{O}$ and INC maximum power point tracking techniques for grid-connected PV systems, (2019)

16. T.S.Babu, N.Rajasekar, K.Sangeetha, AC, Modified particle swarm optimization technique based maximum power point tracking for uniform and under partial shading condition, 34 (2015)

17. M.Francisco, II CIBELEC, Model of Photovoltaic module in Matlab, (2005)

18. A.Bellini, S.Bifaretti, V.Iacovone, C.Cornaro, Simplified Model of a photovoltaic Module, (2014) 